\title{
COMUNIDADE VIRTUAL VERSUS COMUNIDADE PRESENCIAL - UMA VISÃO EM QUATRO DIMENSÕES
}

Virtual community versus presential community - a vision in four dimensions

Marcelo Pupim Gozzi* Maria da Graça Nicoletti Mizukami**

\section{Resumo}

Este artigo mostra uma comparação entre duas comunidades, uma desenvolvida presencialmente e outra virtualmente, objetivando verificar os pontos convergentes e divergentes entre ambas, quando visionadas através de quatro dimensões: formação da identidade do grupo; percepção dos limites individuais; definição do foco que mantém a comunidade ativa; e desenvolvimento da responsabilidade comum. Ele vem contribuir para o entendimento das potencialidades das comunidades virtuais, capazes de agrupar pessoas dispersas geograficamente, com baixo custo e flexibilidade temporal de acesso.

Através de uma pesquisa de natureza qualitativa em uma comunidade virtual de prática de um curso a distância mediado por computador e Internet, foi possível fazer uma descrição analítica- sintética do processo de

\footnotetext{
*Coordenador da Pós-graduação e Professor da Universidade Nove de Julho (UNINOVE); doutorando em Educação pela Universidade de São Paulo (USP); mestrado em Educação, Arte e História da Cultura pela Universidade Mackenzie; técnico da Fundação do Desenvolvimento Administrativo (Fundap). Email: mgozzi@fundap.sp.gov.br.

** Professora da Universidade Federal de São Carlos (UFSCAR) e da Universidade Mackenzie; pósdoutorado pela Santa Clara University, Califórnia, Estados Unidos; doutorado em Ciências Humanas e mestrado em Educação pela Pontifícia Universidade Católica do Rio de Janeiro. Email: gramizuka@ gmail.com.
} 
construção de um projeto coletivo neste curso, possibilitando visualizar e analisar o desenvolvimento desta comunidade virtual nas quatro dimensões citadas, comparando com o resultado de uma pesquisa realizada em uma comunidade presencial.

Os resultados mostram a comparação no desenvolvimento das duas comunidades, ressaltando a importância da mediação pedagógica e da interface virtual do ambiente para o favorecimento da construção de projetos coletivos em comunidades virtuais de prática.

Palavras-chave: Comunidade virtual. Comunidade presencial. Comunidades. Mediação. Educação a distância.

\section{Abstract}

This article shows a comparison between two communities, one developed presentially and the other one virtually. The objective was to verify the convergent and divergent points between both communities, when considering four dimensions: group identity constitution; individual limits perception; definition of focus that keeps community active, and development of common responsibility. It contributes for the understanding of the virtual communities potentialities, grouping people geographically dispersed, with low cost and time access flexibility. Through a qualitative nature research in a virtual practical community in a mediated by computer and Internet distance course, it was possible to make a synthetic analytical description of a collective project construction in this way, allowing to view and to analyze the development of this virtual community in that four dimensions, comparing with the results of another research conducted in a presential community. The results show the comparison in the development of the two communities, emphasizing the importance of educational mediation and virtual interface environment favoring the construction of collective projects in virtual communities of practice.

Keywords: Virtual community. Presential community. Community. Mediation. Elearning. 


\section{INTRODUÇÃO}

A sociedade contemporânea, denominada sociedade do conhecimento, traz a informação como insumo básico e fundamental para o desenvolvimento individual pessoal e profissional, bem como para o desenvolvimento coletivo em todos os aspectos. Essa sociedade pode ser entendida a partir de um diálogo com Flecha e Tortajada:

Na sociedade industrial, havia um predomínio do setor secundário (indústria) e um crescimento do terciário (serviços) em detrimento do setor primário (agricultura, pesca, mineração etc). Atualmente, está desenvolvendose um novo setor (quaternário ou informacional), em que a informação é a matéria-prima e o seu processamento é a base do sistema econômico. (Flecha, Tortajada, 2000, p.22)

Esses autores nos ajudam a refletir o quão importante se torna o acesso à informação na atual sociedade para que os indivíduos possam construir seu conhecimento a fim de tornarem-se cada vez mais empreendedores, conectivos e ativos nesta sociedade do século XXI. Nesse sentido, o desenvolvimento de comunidades tem se mostrado importante na medida que favorece a aprendizagem e o desenvolvimento profissional de grupos de pessoas que, de forma colaborativa, socializam informações para a construção de novos conhecimentos.

As comunidades favorecem o acesso às informações compartilhadas para que, fazendo uso de suas experiências, formações e valores construídos durante sua vida toda, os indivíduos possam construir novos conhecimentos. Podemos apropriar do conceito de Angeloni (2003, p.XV), que argumenta que "conhecimento não é sinônimo de acúmulo de informações, mas um agrupamento articulado delas por meio da legitimação empírica, cognitiva e emocional".

Podemos caracterizar a sociedade do conhecimento pela necessidade do desenvolvimento do senso de coletividade, disponibilizando a matériaprima informação para que possa ser socializada e compartilhada de forma eficiente e rápida, através da aplicação de meios tecnológicos e, 
quando associadas a experiências de vida dos indivíduos, promova uma aprendizagem significativa e permanente.

As novas tecnologias, em especial a Internet, têm ampliado as possibilidades de constituição de comunidades, conhecidas como comunidades virtuais, em virtude da quebra das barreiras espaciais e temporais proporcionadas pelas redes de computadores. Segundo Kenski,

as redes, mais do que uma interligação de computadores, são articulações gigantescas entre pessoas conectadas com os mais diferenciados objetivos. A Internet é o ponto de encontro e dispersão de tudo isso. Chamada de rede das redes, a Internet é o espaço possível de integração e articulação de todas as pessoas conectadas com tudo o que existe no espaço digital, o ciberespaço. (2007, p.34)

Assim como essa autora, Levy (1999) denomina de ciberespaço a Internet e todo o conjunto de elementos que viabilizam o seu acesso e o seu uso, o qual, segundo ele, suporta tecnologias intelectuais capazes de dinamizar e possibilitar ampliações e modificações em diversas funções cognitivas do ser humano (a memória, a imaginação, a percepção, o raciocínio), favorecendo novas formas de acesso à informação e novos estilos de raciocínio e conhecimento. Lévy afirma que:

como essas tecnologias intelectuais, sobretudo as memórias dinâmicas, são objetivadas em documentos digitais ou programas disponíveis na rede (ou facilmente reproduzíveis e transferíveis), podem ser compartilhadas entre numerosos indivíduos, e aumentam, portanto, o potencial de inteligência coletiva dos grupos humanos. (1999, p.157)

Esse pensamento de Lévy nos remete aos benefícios das comunidades virtuais na busca do aprendizado, tanto acadêmico como o profissional. Essas comunidades têm um enorme potencial para a exploração e construção do conhecimento entre grupos e equipes através da colaboração entre seus membros, viabilizadas pelos recursos tecnológicos possibilitados pelas redes de computadores e, em especial, a Internet.

Dialogando com Almeida, podemos observar que: 
o advento das tecnologias de informação e comunicação (TIC) reavivou as práticas de EAD devido à flexibilidade do tempo, quebra de barreiras espaciais, emissão e recebimento instantâneo de materiais, o que permite realizar tanto as tradicionais formas mecanicistas de transmitir conteúdos, agora digitalizados e hipermidiáticos, como explorar o potencial de interatividade das TIC e desenvolver atividades a distância com base na interação e na produção de conhecimento. (2003, p.330)

Podemos perceber, então, que os indivíduos têm novas possibilidades de interatividade com o avanço das TIC e, por meio de uma relação interativa com os equipamentos (computadores), têm viabilizados conteúdos digitalizados em seu monitor, os quais são transmitidos através do acesso à Internet. Mas as possibilidades das comunidades virtuais não se esgotam nesta facilidade de distribuição de conteúdos digitais. Elas se estendem para as facilidades de interação entre as pessoas, possibilitando a construção do conhecimento e a produção de trabalhos em equipe.

Objetivando aprofundar o entendimento das oportunidades de construção de conhecimento oferecidas pelas comunidades virtuais, este artigo vem confrontar o resultado de uma pesquisa realizada durante o acompanhamento de uma comunidade presencial por Grossman et al. (2001) com outra que realizamos em uma comunidade virtual de prática de um curso a distância mediado por computador e Internet.

Grossman et al. (2001), por meio de uma pesquisa em que acompanhou a formação e o desenvolvimento de uma comunidade de aprendizagem presencial, definiram um modelo de formação de comunidades profissionais. A pesquisa envolveu a análise, pelo período de dezoito meses, da atuação de 22 professores, os quais se encontravam presencialmente duas vezes por mês, com o objetivo de aperfeiçoar seus conhecimentos na busca do desenvolvimento profissional. A análise do processo de constituição e desenvolvimento dessa comunidade teve como foco quatro dimensões:

- formação da identidade do grupo e normas de interação;

- navegação pelos limites e entendimento das diferenças;

- negociação do foco da comunidade; e 
individual.

- sentimento de responsabilidade comum pelo crescimento

O modelo sugerido pelos autores considera a análise do desenvolvimento dessa comunidade em função do tempo, olhando sobre essas quatro dimensões, levantando as características relativas ao momento inicial, de evolução e de maturidade da comunidade para cada dimensão.

A pesquisa na comunidade virtual foi realizada na comunidade de prática do curso de Governo Eletrônico ${ }^{1}$ da Fundap ${ }^{2}$, oferecido na modalidade a distância mediado por computador e Internet. Foi realizado o acompanhamento de um grupo de nove alunos que construíram um projeto coletivo nesta comunidade virtual no período de 12 meses. Esse grupo se formou na comunidade de aprendizagem do curso e desenvolveu seu projeto num espaço dessa comunidade destinado ao desenvolvimento de projetos práticos, denominado comunidade de prática. O projeto desenvolvido por esse grupo é parte integrante dos resultados do curso e representa uma oportunidade de aplicação de governo eletrônico no âmbito da administração pública.

Foram identificadas as fases de construção desse projeto, desde a constituição do grupo até a sua conclusão, com as respectivas ações que caracterizaram cada uma dessas fases. Os dados coletados foram compostos por todas as mensagens postadas pelos participantes deste grupo na comunidade virtual do referido curso, desde o período de constituição do grupo até a data da apresentação final do projeto. As mensagens foram associadas a ações desencadeadas pelos participantes do grupo que desenvolveu o projeto, e foram analisadas considerando as características da mediação pedagógica presentes nesse ambiente virtual, bem como as características da interface virtual que permite a conexão entre os participantes e formadores nessa comunidade virtual, conforme consta em Gozzi (2006). Através da descrição analítica-sintética de natureza qualitativa deste processo, foi possível caracterizá-lo. A seguir, esse processo foi comparado a um modelo de formação de uma comunidade de profissionais constituída e desenvolvida presencialmente, no sentido de identificar características importantes da constituição e do desenvolvimento dessa comunidade no âmbito virtual voltada para a implementação do projeto 
coletivo proposto. Esta pesquisa, dentre outros resultados, possibilitou olhar para as mesmas quatro dimensões discutidas para a comunidade presencial por Grossman et al. (2001).

Neste sentido, este artigo vem apresentar, em primeiro plano, o detalhamento dos resultados da pesquisa de Grossman et al. (ibid).

A seguir, são apresentados os resultados da pesquisa realizada na comunidade virtual de prática do curso de Governo Eletrônico da Fundap, discutidos nas quatro dimensões apresentadas por Grossman et al. (ibid).

Como conclusão, é apresentado o confronto dos resultados obtidos nas duas pesquisas, considerando as mesmas quatro dimensões tratadas, visando estabelecer um modelo de formação de uma comunidade virtual, considerando as dimensões citadas.

\section{A COMUNIDADE PRESENCIAL}

Como um dos resultados da pesquisa realizada na comunidade presencial, Grossman et al. (Ibid) definiram o modelo de formação da comunidade de profissionais, conforme síntese apresentada na Figura 1.

Considerando a dimensão relativa à formação da identidade do grupo e das normas de interação, Grossman et al. (Ibid) explicam que, na comunidade pesquisada, os professores identificavam-se inicialmente com subgrupos como, por exemplo, os membros de seu departamento. Nesse momento inicial de formação dessa comunidade, a entrada ou a saída de um membro do grupo não era caracterizada como uma perda para o grupo. Conforme essa comunidade evoluía, seus membros começaram a reconhecer as diferentes contribuições individuais para o grupo, o que os permitiu enxergar a responsabilidade de cada indivíduo para o funcionamento da comunidade. Essas percepções levaram essa comunidade a estabelecer as suas regras e normas, inclusive as relativas ao comportamento.

Em relação à navegação através dos limites na comunidade, Grossman et al. (Ibid.) citaram que no início da vida da comunidade de professores em questão observou-se um falso senso de união. Esse sentimento foi caracterizado como falso porque surgiam conflitos, como em qualquer grupo de pessoas, em virtude das diferenças, as quais se tornaram cada vez mais difíceis de ser ignoradas. Com a evolução da comunidade, esses 
MODELO DE FORMAÇÃO DA COMUNIDADE PROFISSIONAL DE PROFESSORES

\begin{tabular}{|c|c|c|c|}
\hline Dimensão & Início & Evolução & Maturidade \\
\hline $\begin{array}{l}\text { Formação da } \\
\text { identidade do grupo e } \\
\text { das normas de } \\
\text { interação }\end{array}$ & $\begin{array}{l}\text {-Identificação com subgrupos; } \\
\text {-Ausência do sentimento de perda } \\
\text { de elementos do grupo; } \\
\text {-Há uma tendência à indelicadeza; } \\
\text {-Senso de individualismo } \\
\text { sobrepöe a responsabilidade do } \\
\text { trabalho em grupo. }\end{array}$ & $\begin{array}{l}\text {-Falso senso de unidade do grupo; } \\
\text {-Reconhecimento de raras } \\
\text { contribuiçöes individuais; } \\
\text {-Discussão aberta das normas de } \\
\text { interaçäo; } \\
\text {-Reconhecimento da necessidade } \\
\text { de criar regras de comportamento. }\end{array}$ & $\begin{array}{l}\text {-Reconhecimento da riqueza das } \\
\text { múltiplas perspectivas individuais; } \\
\text {-Sentimento de perda de } \\
\text { elementos do grupo; } \\
\text {-Desenvolvimento de normas de } \\
\text { interaçăo; } \\
\text {-Responsabilidade comum. }\end{array}$ \\
\hline $\begin{array}{l}\text { Navegando pelos } \\
\text { limites individuais }\end{array}$ & $\begin{array}{l}\text {-As diferenças individuais são } \\
\text { negadas; } \\
\text {-0s conflitos são discutidos em } \\
\text { segundo plano; } \\
\text {-Falso senso de unidade. }\end{array}$ & $\begin{array}{l}\text {-Apropriaçäo de pontos de vista } \\
\text { diferentes por uma posiçäo } \\
\text { dominante; } \\
\text {-Surgem conflitos, os quais são } \\
\text { temidos. }\end{array}$ & $\begin{array}{l}\text {-Uso produtivo e entendido das } \\
\text { diferenças individuais; } \\
\text {-0 conflito é um elemento } \\
\text { esperado na vida do grupo e é } \\
\text { negociado com transparência e } \\
\text { honestidade. }\end{array}$ \\
\hline $\begin{array}{l}\text { Negociando o foco } \\
\text { que mantém a } \\
\text { comunidade ativa }\end{array}$ & $\begin{array}{l}\text {-Falta de entendimento sobre a } \\
\text { proposta da comunidade } \\
\text { profissional; } \\
\text {-As diferentes posiçöes } \\
\text { individuais säo entendidas como } \\
\text { um antagonismo inerente. }\end{array}$ & $\begin{array}{l}\text {-Disposição invejável para permitir } \\
\text { que pessoas diferentes } \\
\text { desempenhem atividades } \\
\text { diferentes. }\end{array}$ & $\begin{array}{l}\text {-Definiçäo e reconhecimento do } \\
\text { foco da comunidade. }\end{array}$ \\
\hline $\begin{array}{l}\text { Desenvolvendo } \\
\text { responsabilidade } \\
\text { comum pelo } \\
\text { crescimento individual }\end{array}$ & $\begin{array}{l}\text {-Crença de que a responsabilidade } \\
\text { do professor é com os alunos e } \\
\text { não com os demais professores; } \\
\text {-0 crescimento intelectual é } \\
\text { responsabilidade do indivíduo; } \\
\text {-As contribuiçöes com o grupo } \\
\text { säo açöes desencadeadas por } \\
\text { vontades individuais. }\end{array}$ & $\begin{array}{l}\text {-Reconhecimento de que os } \\
\text { colegas do grupo são fontes para } \\
\text { o aprendizado individual; } \\
\text {-Reconhecimento de que a } \\
\text { participação na comunidade é } \\
\text { esperada por todos. }\end{array}$ & $\begin{array}{l}\text {-Comprometimento com o } \\
\text { crescimento dos colegas; } \\
\text {-Aceitação dos direitos e deveres } \\
\text { dos membros da comunidade. }\end{array}$ \\
\hline
\end{tabular}

Figura 1 - Modelo de formação da comunidade profissional de professores (GROSSMAN et al., 2001)

professores passaram a entender as diferenças como variações em torno de um ponto de vista dominante. Com o amadurecimento da comunidade, as diferenças passaram a ser compreendidas pelos participantes como um elemento produtivo para o grupo, auxiliando no entendimento do grupo como um todo, rompendo os limites entre subgrupos da comunidade.

Em relação à definição do foco dessa comunidade, Grossman et al. (2001) argumentam que, no início de sua formação, os professores não perceberam a importância do aprendizado para o professor. $\mathrm{O}$ foco era a aprendizagem do aluno. Com a evolução da comunidade em relação a essa dimensão, os professores começaram a descobrir a importância do aprendizado do aluno associado ao aprendizado da docência, identificando dois pólos com valores diferentes que caminham para um mesmo objetivo. $\mathrm{O}$ amadurecimento da comunidade levou-os a definir o foco da comunidade, 
percebendo a importância do aprendizado profissional do professor como recurso para o desenvolvimento de melhores práticas relacionadas à aprendizagem dos alunos.

Analisando a comunidade do ponto de vista da quarta dimensão - sentimento de responsabilidade comum pelo crescimento individual -, Grossman et al. (Ibid.) perceberam que, inicialmente, os professores consideravam que sua responsabilidade estava centrada nas necessidades dos alunos, e não na aprendizagem profissional do grupo que compunha essa comunidade. Eles acreditavam que o crescimento profissional era uma responsabilidade individual do professor e as colaborações na comunidade ficavam restritas à vontade de cada professor em contribuir para o aprendizado dos demais colegas. Com a evolução da comunidade, os professores reconheceram seus direitos e deveres como membro da comunidade, comprometendo-se com o desenvolvimento profissional dos demais colegas através das discussões e colaborações na comunidade.

Cabe aqui, portanto, enfatizar que o modelo de formação dessa comunidade profissional, desenhado com foco nas quatro dimensões abordadas, é um parâmetro importante para discutir um modelo de formação e desenvolvimento de uma comunidade virtual, pois permite comparar as ocorrências no ambiente virtual, mantendo o foco nessas mesmas dimensões, conforme discutiremos no decorrer deste estudo.

\section{A COMUNIDADE VIRTUAL}

Conforme proposto no início desta análise, portanto, passamos a identificar as ocorrências desenhadas por um grupo de nove participantes ${ }^{3}$, que desenvolveu um projeto coletivo no período de 12 meses, na comunidade virtual de prática do curso de Governo Eletrônico da Fundap, relativamente às quatro dimensões estudadas por Grossman et al. (2001) quando pesquisaram uma comunidade presencial de professores.

Esse projeto foi desenvolvido por esse grupo, denominado "grupo 4" no referido curso, em cinco fases.

A atuação do grupo 4 na comunidade de aprendizagem do curso de Governo Eletrônico nos permite observar os seguintes fatos ocorridos com base nas quatro dimensões: 


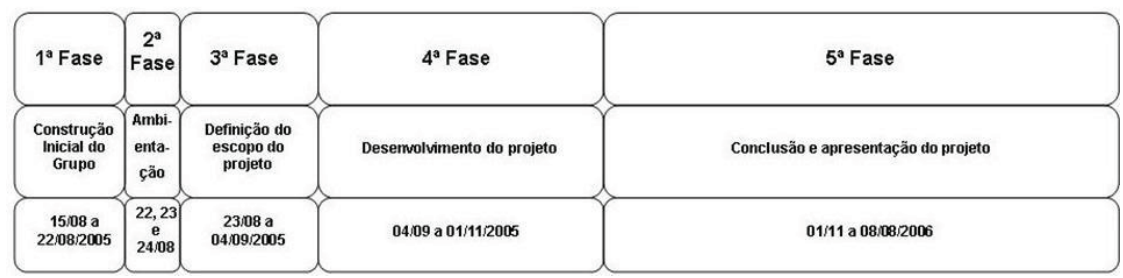

Figura 2 - Fases do processo de construção do projeto coletivo do Grupo 4 do curso de Governo Eletrônico da Fundap

- $1^{\text {a }}$ dimensão - Formação da identidade do grupo e das normas de interação: a primeira fase do processo foi marcada pela vontade do coordenador do grupo formar o grupo para desenvolver o projeto. Suas ações relativas aos convites para a integração dos participantes para composição do grupo foram freqüentes e constantes e contaram com 0 apoio do mediador pedagógico ${ }^{4}$ da comunidade. Nesse início, esse coordenador impôs o ritmo das interações na comunidade que ele esperava constituir. Na segunda fase, ele manteve o ritmo das interações e recepcionou os participantes que se manifestaram na busca de ambientação, mostrando a importância de constituir um grupo em que o diálogo estivesse em sua essência. Correspondeu a todos, sempre com muito respeito, honestidade e franqueza, o que pode ser observado nas mensagens que compõem os episódios da segunda fase. Esses conceitos, segundo Palloff \& Pratt (2002), garantem as condições para existência e manutenção de uma comunidade virtual. Apesar do seu esforço, entretanto, alguns participantes ainda não tinham se manifestado. Porém, os demais participantes mostravamse muito dispostos a colaborar com o projeto. Ainda, na segunda fase do processo, tanto o coordenador do grupo quanto o mediador pedagógico incentivavam os participantes a transitarem pelo ambiente para o contato com as primeiras tarefas propostas, o que demonstrou a definição de algumas normas de interação do grupo relativas ao uso das ferramentas do ambiente Teleduc ${ }^{5}$, no qual se desenvolvia essa comunidade virtual. Na terceira fase do processo, as colaborações individuais para o desenvolvimento do escopo do projeto surgiram 
na comunidade com alta freqüência e rapidez. Um episódio mostrou, também, que uma ausência de participação foi percebida pelos participantes da comunidade. Ao consolidar o escopo do projeto, foi notada a importância das contribuições individuais para os objetivos do grupo. Nesse momento, os participantes já se identificavam com o grupo todo e as normas de interação estavam definidas e incorporadas pelo grupo. Nas fases seguintes foi possível observar que essas normas iam sendo ajustadas conforme as possibilidades de melhoria iam sendo percebidas pelo grupo. A participação distribuída de todos os participantes durante as duas fases finais do processo de construção do projeto coletivo demonstrou o senso de responsabilidade comum em relação aos objetivos da comunidade;

- $\quad 2^{\mathrm{a}}$ dimensão - Navegando pelos limites individuais: no período de construção inicial do grupo, seu coordenador sinaliza a importância do respeito às diferentes opiniões individuais quando propôs que 0 nome do projeto deveria ser discutido com os demais participantes. Isso demonstra que entende as diferenças individuais e sabe 0 valor dessas diferenças para a construção do projeto coletivo. $\mathrm{O}$ coordenador do grupo se disse aberto à discussão de tudo com todos, reconheceu a importância das diferenças individuais, mostrando que o diálogo é fundamental para fazer um bom uso dessas diferenças. Durante o desenvolvimento das três fases iniciais desse processo, 0 grupo mostrou-se muito unido, não tendo sido notado qualquer tipo de conflito entre os participantes. Dificuldades expressas relativas às poucas ausências de participação na comunidade são entendidas por todos. Na quarta fase do processo, observamos dois conflitos. Em ambos os casos, as diferenças desencadeadoras do conflito foram discutidas de forma clara e honesta, gerando resultados positivos. $\mathrm{Na}$ última fase desse processo, um novo conflito foi observado, relativo à cobrança de colaboração dos participantes por parte do coordenador do grupo, em virtude de ausências na comunidade virtual. Esse conflito também foi resolvido de forma bastante transparente e desencadeou o agendamento de uma reunião presencial que trouxe bons resultados para o desenvolvimento do projeto; 
- $\quad 3^{\text {a }}$ dimensão - Negociando o foco que mantém a comunidade ativa: o foco do projeto foi pré-definido pelo coordenador do grupo quando propôs a constituição da comunidade para o seu desenvolvimento. A escolha pela participação no grupo 4, realizada na primeira fase do processo analisado, estava diretamente relacionada com a vontade do participante do curso em desenvolver o tema proposto, seja pela afinidade, pelo desafio ou por qualquer outro interesse de ordem pessoal. Simultaneamente, todos os participantes, ao acessar o curso, sabiam da proposta de desenvolvimento de um trabalho prático nessa comunidade virtual, o que compunha, inclusive, o processo de avaliação do curso. Isso justifica o fato de a discussão do escopo do projeto ter-se iniciado de forma tão rápida nessa comunidade virtual, assim como a facilidade com que se desenvolveu essa terceira fase desse processo. Portanto, o foco que manteve essa comunidade ativa foi a proposta de desenvolvimento do projeto, entendida por todos os participantes que aderiram ao grupo, e esse foco foi também aperfeiçoado nessa fase, quando foi definido 0 escopo do projeto a ser desenvolvido nessa comunidade virtual;

- $4^{\mathrm{a}}$ dimensão - Desenvolvendo responsabilidade comum pelo crescimento individual: para entendermos como ocorreu 0 desenvolvimento da comunidade virtual constituída pelo grupo em estudo no curso de Governo Eletrônico da Fundap em relação a essa dimensão, precisamos fazer as seguintes considerações:

a) o processo de construção inicial do grupo 4 iniciou-se em 15/8/2005, ou seja, 45 dias após o início do curso;

b) os participantes desse grupo estavam interagindo com os demais participantes do curso na comunidade de aprendizagem desde o início do curso; e

c) conforme proposto no plano do curso de Governo Eletrônico, a tônica de sua comunidade de aprendizagem é a colaboração mútua entre participantes e formadores, fazendo com que todos se sintam comprometidos com o processo de aprendizagem de todos que participam dessa comunidade. 
Essas considerações são importantes para observar que os participantes do grupo 4, quando interessados em participar do desenvolvimento do projeto proposto pelo coordenador, já haviam experimentado o processo de aprendizagem colaborativa proposto para esse curso, tendo verificado que cada indivíduo é importante para o desenvolvimento da comunidade virtual e, conseqüentemente, dos demais participantes do curso. Nesse sentido, percebemos logo nos episódios iniciais da $2^{\mathrm{a}}$ fase do processo analisado a grande disposição por parte dos participantes que se manifestaram, voltada para a colaboração com o grupo. Nessa fase, o coordenador do grupo, apoiado pelo mediador pedagógico, orientou e colaborou para o crescimento dos demais participantes em relação aos conhecimentos e à ambientação necessária para o início do desenvolvimento do projeto. As ajudas solicitadas para a ambientação individual são exemplos do reconhecimento que os demais participantes da comunidade eram considerados fontes importantes para 0 aprendizado individual. Essa crença esteve presente em todas as fases do processo.

\section{CONCLUSÕES}

Após a análise do processo de construção do projeto do grupo 4 no curso de Governo Eletrônico da Fundap, focando o desenvolvimento dessa comunidade virtual a partir das quatro dimensões que Grossman et al. (2001) analisaram em uma comunidade presencial, foi possível estabelecermos uma comparação entre 0 modelo desenvolvido por Grossman et al. (Ibid.), relativo à formação da comunidade num ambiente presencial, e as ocorrências da comunidade constituída pelo grupo 4 no ambiente virtual, cujas conclusões a respeito estão sintetizadas nos quadros comparativos a seguir:

Como resultado dessa comparação temos:

- as regras preestabelecidas para organização do ambiente virtual da comunidade de aprendizagem do curso de Governo Eletrônico da Fundap, a atuação dos mediadores pedagógicos e a atuação do coordenador do grupo 4, que assumiu o papel de mediador pedagógico, favoreceram a definição das normas de interação do grupo nessa comunidade virtual; 


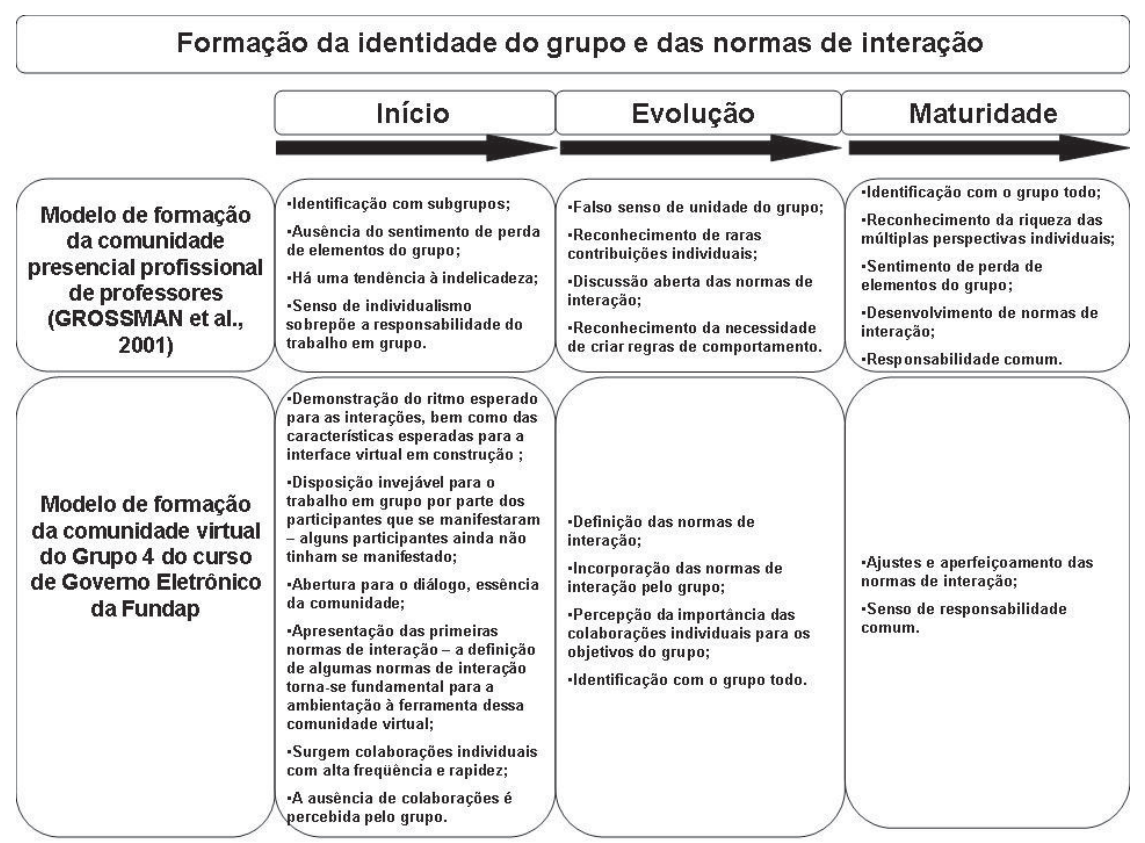

Figura 3 - Quadro comparativo - Formação da identidade do grupo e das normas de interação

- a experiência e a vivência dos participantes na comunidade de aprendizagem do curso de Governo Eletrônico da Fundap, orientados pelos mediadores pedagógicos antes de constituírem o grupo 4 com o objetivo de desenvolver o projeto prático, foram importantes para favorecer a formação da identidade do grupo; também foram fundamentais para que os participantes entendessem que a colaboração individual é importante para o crescimento intelectual de todos;

- a atuação do coordenador do grupo, assumindo o papel de mediador pedagógico, foi fundamental para o estabelecer uma interface virtual honesta e respeitosa, favorecendo o reconhecimento da existência e importância das diferenças individuais para o desenvolvimento do 


\begin{tabular}{|c|c|c|c|}
\hline \multicolumn{4}{|c|}{ Navegando pelos limites individuais } \\
\hline & Início & Evolução & Maturidade \\
\hline $\begin{array}{l}\text { Modelo de formação } \\
\text { da comunidade } \\
\text { presencial profissional } \\
\text { de professores } \\
\text { (GROSSMAN et al., } \\
\text { 2001) }\end{array}$ & $\begin{array}{l}\text {-As diferenças individuais são } \\
\text { negadas; } \\
\text {-0s conflitos são discutidos em } \\
\text { segundo plano; } \\
\text {-Falso senso de unidade. }\end{array}$ & $\begin{array}{l}\text {-Apropriação de pontos de vista } \\
\text { diferentes por uma posiçäo } \\
\text { dominante; } \\
\text {-Surgem conflitos, os quais são } \\
\text { temidos. }\end{array}$ & $\begin{array}{l}\text {-Uso produtivo e entendido das } \\
\text { diferenças individuais; } \\
\text {-0 conflito é um elemento } \\
\text { esperado na vida do grupo e é } \\
\text { negociado com transparência e } \\
\text { honestidade. }\end{array}$ \\
\hline $\begin{array}{l}\text { Modelo de formação } \\
\text { da comunidade virtual } \\
\text { do Grupo } 4 \text { do curso } \\
\text { de Governo Eletrônico } \\
\text { da Fundap }\end{array}$ & $\begin{array}{l}\text {-Reconhecimento da existência e } \\
\text { da importância das diferenças } \\
\text { individuais; } \\
\text {-Demonstraçäo de respeito às } \\
\text { diferenças individuais; } \\
\text {-Não foram identificados conflitos. }\end{array}$ & $\begin{array}{l}\text {-As dificuldades individuais säo } \\
\text { entendidas por todos. }\end{array}$ & $\begin{array}{l}\text { quais foram discutidos de forma } \\
\text { clara, honesta, pertinente e franca, } \\
\text { conforme as caracteristicas da } \\
\text { interface virtual estabelecida pelo } \\
\text { grupo nessa comunidade; } \\
\text { - A solução dos conflitos } \\
\text { reverteram em resultados } \\
\text { positivos para o desenvolvimento } \\
\text { do projeto. }\end{array}$ \\
\hline
\end{tabular}

Figura 4 - Quadro comparativo - Navegando pelos limites individuais

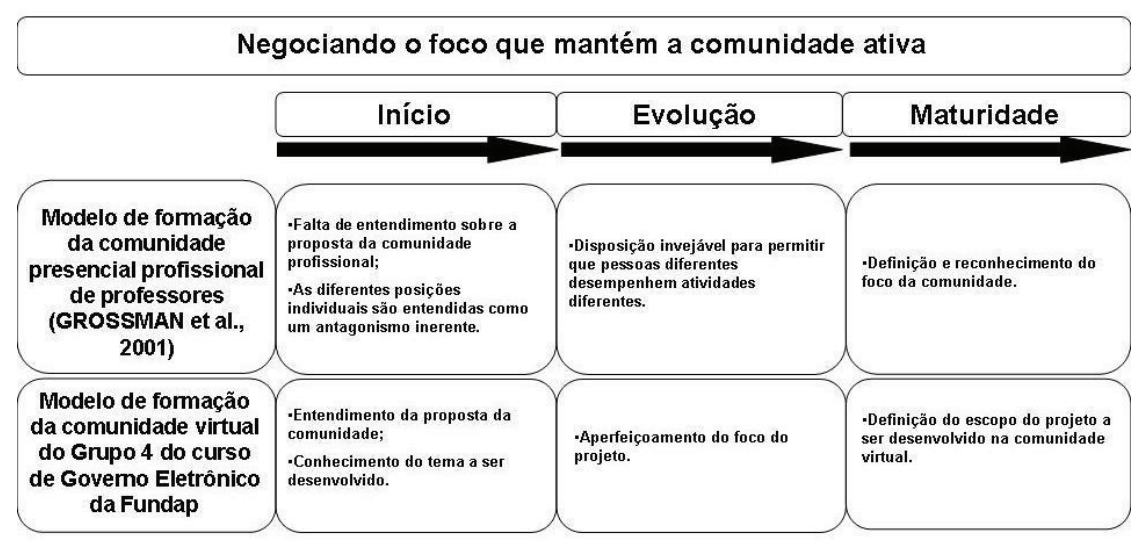

Figura 5 - Quadro comparativo - Negociando o foco que mantém a comunidade ativa

projeto coletivo; seu comportamento também foi fundamental para a gestão dos poucos conflitos que ocorreram nessa comunidade, os quais reverteram em resultados positivos para o desenvolvimento do projeto; 


\section{Desenvolvendo responsabilidade comum pelo crescimento individual}

\begin{tabular}{|c|c|c|c|}
\hline & Início & Evolução & Maturidade \\
\hline $\begin{array}{l}\text { Modelo de formação } \\
\text { da comunidade } \\
\text { presencial profissional } \\
\text { de professores } \\
\text { (GROSSMAN et al., } \\
\text { 2001) }\end{array}$ & $\begin{array}{l}\text { - Crença de que a responsabilidade } \\
\text { do professor é com os alunos e } \\
\text { näo com os demais professores; } \\
\text {-0 crescimento intelectual é } \\
\text { responsabilidade do individuo; } \\
\text {-As contribuiçöes com o grupo } \\
\text { são açöes desencadeadas por } \\
\text { vontades individuais. }\end{array}$ & $\begin{array}{l}\text {-Reconhecimento de que os } \\
\text { colegas do grupo são fontes para } \\
\text { o aprendizado individual; } \\
\text {-Reconhecimento de que a } \\
\text { participação na comunidade é } \\
\text { esperada por todos. }\end{array}$ & $\begin{array}{l}\text {-Comprometimento com o } \\
\text { crescimento dos colegas; } \\
\text {-Aceitação dos direitos e deveres } \\
\text { dos membros da comunidade. }\end{array}$ \\
\hline $\begin{array}{l}\text { Modelo de formação } \\
\text { da comunidade virtual } \\
\text { do Grupo } 4 \text { do curso } \\
\text { de Governo Eletrônico } \\
\text { da Fundap }\end{array}$ & $\begin{array}{l}\text {-Crença de que a colaboração } \\
\text { mútua é importante para o } \\
\text { aprendizado individual; } \\
\text {-A cultura da colaboração voltada } \\
\text { para o aprendizado já estava } \\
\text { desenvolvida nos participantes do } \\
\text { grupo. }\end{array}$ & \multicolumn{2}{|c|}{$\begin{array}{l}\text { Ações constantes demonstram que todos os participantes são fontes } \\
\text { importantes para o crescimento individual de todos os participantes do } \\
\text { grupo. }\end{array}$} \\
\hline
\end{tabular}

Figura 6 - Quadro comparativo - Desenvolvendo responsabilidade comum pelo crescimento individual

- a definição da proposta dessa comunidade virtual no curso estudado e a apresentação da proposta do projeto elaborada pelo coordenador do grupo favoreceram a negociação do foco que manteve a comunidade ativa, o que ocorreu na terceira fase do processo de construção desse projeto coletivo, quando foi definido o escopo do projeto a ser desenvolvido.

Ainda, a comunidade virtual de aprendizagem do curso de Governo Eletrônico da Fundap contribuiu para o desenvolvimento do projeto do grupo 4 no seu espaço denominado comunidade de prática, porque esta estava apoiada na mediação pedagógica desenvolvida pelos formadores e participantes, numa interface virtual com excelência de qualidade e nos recursos tecnológicos adequados para viabilizar e facilitar a boa comunicação e a interação dos atores do curso.

As considerações e observações tecidas através desta análise, portanto, permitem ressaltar que uma comunidade virtual de prática pode favorecer a construção de projetos coletivos em diversas áreas da ciência, da mesma maneira como concorreu para o desenvolvimento do projeto do grupo 4 no curso de Governo Eletrônico da Fundap. 


\section{REFERÊNCIAS}

ALMEIDA, Maria Elizabeth Bianconcini. Educação a distância na Internet: abordagens e contribuições dos ambientes digitais de aprendizagem. Educação e Pesquisa, São Paulo, 2003.

ANGELONI, Maria Terezinha (Org.). Organizações do Conhecimento: infraestrutura, pessoas e tecnologia. São Paulo: Saraiva, 2003.

FLECHA, R.; TORTAJADA, I. Desafios e saídas educativas na entrada do século. In: IMBERNÓN, Francisco (org.). A EDUCAÇÃO NO SÉCULO XXI - Os desafios do futuro imediato. Porto Alegre: Artes Médicas Sul, 2000.

GOZZI, Marcelo Pupim. A construção de um projeto coletivo em uma comunidade virtual de prática. São Paulo, Universidade Mackenzie (Dissertação de Mestrado), 2006.

GROSSMAN, P.; WINEBURG, S.; WOOLWORTH, S.. Toward a Theory of Teacher Community. Teachers College Record, Columbia, v.103, nº. 6, p. 942-1012, Dez. 2001 .

KENSKI, Vani Moreira. Educação e tecnologias: O novo ritmo da informação. Campinas, SP: Papirus, 2007.

LÉVY, Pierre. Cibercultura. São Paulo: Ed. 34, 1999.

PALLOFF, R. M.; PRATT, K. Construindo comunidades de aprendizagem no ciberespaço. Porto Alegre: Artmed, 2002. 